me to draw your attention to the fact that it is not all contained in the report of the inquest, voluminous as it is, which was forwarded to you by Mr. Fox. I was not present at the inquest, and consequently the evidence I gave at the trial does not appear there. I was very anxious not to obtrude anything of a personal nature into my letter, but in consequence of what has fallen from Mr. Fox, I will ask you to allow me to make this short explanation.

I was present at the post-mortem examination only at the request of my partner, Mr. Lister, and should have taken no part in it but that Mr. Morris, who was making it, cut his finger soon after examining the brain, and $I$ then finished the examination. I however watched Mr. Morris in his dissection of the brain, and very carefully noted all the appearances presented. Mr. Morris made the examination in the main exactly as it would be made in a hospital post-mortem room. I knew none of the gentlemen who were present, and had not seen the deceased during his life, and as I did not expect to be called at the inquest, what observations I made were entirely without bias. The appearance of the brain membranes was such as to leave no doubt at all in my mind that acute meningitis had been present, and the facts which I noted were briefly these:That the arachnoid was inflamed, thickened, and covered with patches of effused lymph ; that its layers were adherent, and that there was smearing of turbid serum over the brain. The pia mater was congested, the meningeal vessels turgid - some vascular injection of brain-substance; no effusion in Jateral ventricles. There certainly were adhesions between the layers of arachnoid, and I am sorry that Mr. Fox should vaguely hint that when he admitted there were these several "filaments or pieces," not being "bloodvessels," between the layers of arachnoid, he was thinking of the Pacchionian glands. He did indeed attempt to prove that there might be these filaments in the bealthy brain, but his friend Dr. Leech was obliged to differ from him about that, as $I$ also believe do the numerous anatomical authorities Mr. Fox has so kindly recommended to my notice. Will you allow me also to point out another difference of some importance between Dr. Leech and $\mathrm{Mr}$. Fox, who both visited the patient together during his life. Mr. Fox discovered a rose rash, which gradually became, on being asked particularly about it, an "ill-defined one." It was so "ill-defined" that Dr. Leech could see nothing at all of it.

With respect to the value of the evidence given by me, I have been assured, in a communication from one of the three eminent gentlemen to whom Mr. Fox submitted the evidence as given at the inquest, that if my evidence had been given before the coroner, he should have advised the Railway Company not to go into court at all. I therefore feel that the report of the inquest does not convey a correct impression of the relative value of the evidence given at the trial with respect to the "conflict of statements" which appears in the report. I think we none of us perhaps agreed with the description which Mr. Morris gave of the adhesions, since he described them as being firmer and more dense than would be the ease; but for the truth of the broad facts stated by him, I can only say I had the evidence of $m y$ senses, and was in a particularly favourable position for judging correctly.

There are two questions in connexion with this case which seem to $m e$ to be the ones of chief interest. Firstly, does any recognised opinion exist with respect to the condition in which Peyer's patches would be found after death on the sixteenth day of enteric fever? Would the absence of ulceration be sufficient to exclude the existence of the fever for that length of time? Secondly, accepting as facts in a case the existence of congestion of patches and of mucous membrane, but not ulceration, after an acute illness of sixteen days, together with an undeniable previous history of blow on the head, and severe nervous shock, followed by headache more or less persistent till the time of the acute illness, which acute illness might point either to acute meningitis or to enteric fever, but did point to the former for some time before death, and was treated as such by the medical men in regular attendance, and that after death there was found some evidence of recent and acute inflammation of the membranes of the brain, would not the presumption be very strong that death had resulted from traumatic meningitis? - I am, Sir, your obedient servant, Doncaster, September 6th, 1875.

\section{SERJEANT WHEELER ON INSANITY AND FRIENDLY SOCIETIES.}

To the Editor of THE LANCET.

Sin,- You have done good service to the medical profession and the public by calling attention to what you aptly designate the "singular lucidity of statement" in Serjeant Wheeler's summing up and address to the jury in the recent case before him of Lovell v. Behrens, tried in the Marylebone County Court.

This may perhaps be a fitting occasion also to call attention to a judgment of that learned judge delivered in his then court at Liverpool upon the moot question, so im. portant to the poor, whether insanity was bodily sickness, entitling the members of friendly societies to the benefit of the sick fund. The decision then given to this question has not hitherto been brought with sufficient prominence before the public, although I am glad to say that it is now pub. lished in the eighth edition of "Tidd Pratt's Law of Friendly Societies," and will doubtless be extensively read. The state of the question at the time the judgment was de. livered was to this effect: that in the opinion of the late Mr. Tidd Pratt, Registrar of Friendly Societies, and other authorities, "Insanity is not to be regarded as bodily sick. ness, because by sickness is meant a state of bodily disease, and has no reference to lunacy, which is a derangement of the mental faculties."

The judgment of my friend Mr. Serjeant Wheeler was delivered soon after the death of my friend Mr. Tidd Pratt, and is based on physiological grounds, and in accordance with those organic laws of nature, upon a knowledge of which the stability of human laws must depend. "It is necessary," says Serjeant Wheeler, "in considering the question, to bear in mind the natural and essential relations of mind and body. Every manif estation of mind in this life is made by and through its bodily organ, the brain; and the mind is so influenced by the brain that the condition of the former is an invariable index to the constitution and condition of the latter. Hence all causes of temporary or permanent disturbance in the health of those parts of the brain that manifest the mind produce in the same degree the signs of mental derangement, and, vice versâ, all sym. ptoms of mental derangement indicate a proportionate dis. turbance in the sanitary state of the mind's bodily organ the brain. Some years since, when it was the habit to ex. amine the brain with the aid only of the naked eye, it was not possible in many cases to discover those lesions of brain structure which produce and accompany insanity. But now, by the recent application of the microscope, the minute structure of the brain is revealed, and pathologists can trace distinctly the seat and nature of those morbid changes which are the real essence of insanity. Hence Schroeder Van der Kolk, an eminent German anatomist, says that he does not remember to have dissected the brain of one lunatic during the last twenty-five years without finding a satisfactory explanation of the phenomena observed during life.' Dr. A. Combe, in his work 'On Mental Derange. ment,' lays down this principle: 'Every derangement of function is accompanied by disorder, either in the strueture or mode of action of the organ which performs it, and without the removal or cure of which the function cannot be restored to its healthy state.' From ignorance of, or want of confidence in, the fact that the brain is the medium for manifesting mind, our predecessors were contented to regard mental derangement as an affection of the immaterial principle of mind, or as a particular dispensation of Providence which they could not be expected either to understand or to remedy; and, accordingly, while this view continued to influence their practice, all sorts of barbarous and useless measures were adopted against the miserable patients. The latest expression of authoritative opinion upon this subject is Dr. Maudsley's, in his Gulstonian Lectures ' On the Relations between Body and Mind.' That gentleman thus speaks:-CI I have given a survey of the physiology of our mental functions, showing how indissolubly they are bound up with the bodily functions, and how barren must of necessity be the study of mind apart from body. I now propose to show that the phenomena of mental derangement bear out fully this view of its nature, that we have not to deal with disease of a metaphosical entity, which the 
method of inductive inquiry cannot reach, or the resources of medical art touch, but with disease of the nervous system, disclosing itself by physical and mental symptoms. It seems then that the question is concluded both by reasoning and medical testimony, and it appears to me that insanity is just as much bodily disease as paralysis and apoplexy, which are notoriously affections of the brain and therefore admitted to be bodily disease." "

The practical issue of this judgment was an order given by the Secretary of State for granting sick allowance in cases of insanity.

I remain, Sir, your obedient servant,

Great College-Street, Westminster.

$$
\text { W. U. WHITNEY. }
$$

\section{PAYMENT FOR DISTRICT MEDICAL RETURNS.}

\section{To the Editor of THE Lancet.}

SIR,-I have received a letter from the Local Government Board, dated. Sept. 13 th, 1875 , acknowledging my report, in which the following statement occurs, which will, I think, be received with satisfaction both by district medical officers and medical officers of health, and points out the wish of the Local Government Board to interpret the new Public Health Act in a just and liberal spirit.

"Adverting to your remark, on page 28 of the Report, that there seems to be no means in the present law of giving a district medical officer remuneration for information respecting sickness in his district, which he may furnish to the medical officer of bealth, I am directed to state that the Board consider that it is competent for the urban sanitary authority, if they think proper to do so, to enter into an arrangement to pay the district medical officer reasonable remuneration for supplying you, as medical officer of bealth with information which you require for the efficient discharge of your duties."

Feeling that the refusal of the district medical officers, both in my urban and rural sanitary districts, to furnish me with returns was purely a matter of principle, in which I myself sympathised, I thought it right to mention the matter in my report, and it gives me much pleasure to find that it has elicited so important a decision.

I am, Sir, yours faithfully,

Horace SwETE, M.D.

Medical Officer of Health, Droitwich Rural and

Leamington, Sept 14th, 1875. Urban Sanitary Districts.

\section{PARIS.}

(From our own Correspondent.)

MEETING OF THE FRENCH ASSOCIATION FOR THE ADVANCEMENT OF SCIENCE AT NANTES.

THE accounts which have reached Paris of the fifth session of the French Association for the Advancement of Science, recently held at Nantes, all speak of the very great success of the meeting. In all the sections members were most active; several important communications were made, and gave rise to valuable debates. Of the proceedings of the medical section I shall give you a special and condensed account in my next letter. In the section of Anthropology the communications of Professors Vogt and Broca were especially interesting.

The local authorities bad done their best to enhance the interest and attractions of the Nantes meeting, and all the notable inhabitants of the city of the west and its environs had co-operated in ensuring its success, either by joining a members, or exhibiting private collections of art or science or sending invitations to their estates, \&c.

Many sectional or general excursions were made into picturesque old Brittany, full of prehistoric associations and remains and of present attractions. The Agricultural section visited the School of Agriculture of Grandjouan under the guidance of M. Rieffe, who had invited them to luncheon, and the model estates of $M$ de la Haye-Jousselin, who with great courtesy, accompanied them over his grounds.
The anthropologists made two interesting exonrsionsone to the Lac de Grandlieu, where (inter parentheses) they were very nearly arrested by a suspicious gendarme, whose mind was made uneasy by the wanderings of these strangers; the other to the renowned commune of Bourg de Batz, a small peninsula between le Pouliguen and le Croisic, inhabited by the descendants of four or fire families, and remarkable for the robust vigour and developed statire of the inhabitants, especially the women. As the system of intermarriages is exclusively practised there, the handsomeness and strength of the inbabitants bring out the theory that consanguineous marriages are bad only in the case of diseased or degenerated relatives.

One general excursion was a protracted one: it lasted three days, and included Auray, Lorient, Belle-Isle, Vannes, Locmariaquer, and Gaor Inis. The visit to this last locality was especially interesting, on account of its immense dolmens and the curious hieroglyphic figures with which they are covered, and which have until now baftled the interpretation of savants.

It is decided that the next meeting of the Association shall be held at Clermont-Ferrand, amidst the beautiful mountain districts of Auvergne, and that Professor Dumas, the illustrious chemist, will be president.

CONTEMPLATED CATHOLIC UNIVERSITIES.

Great exertions are being made amongst the religious associations and clergy for the rapid foundation of several universities. As you are well aware, a recent vote of the National Assembly has authorised the establishment of free universities besides those belonging to the State. A council of bishops has been held here, and it has been decided that paris shall have its free university, supported by the clergy and including the faculties of law, letters, and sciences, besides courses of medicine. It is expected that the university will be opened in November, one of the clerical organs here, l'Univers, asserting that the requisite number of professors and students already exists. The Bishops of Toulouse have also met for the purpose of founding a like university for the South of France, and those of Anger are likewise busy preparing an establishment in the West.

MEDICAL DESCENT OF MARSHAL MACMAHON.

In the last issue of the Journal des Connaissances Médicales. there was an interesting piece of news touching the medical descent of the President of the French Republic, who, according to the article, is descended from, or nearly related to, several medical men. Thus his grandfather, Jean Baptiste MacMahon, was a medical man, and a Doctor of the Faculty of Reims; his grand uncle, Dr. Jean MacMahon, was a graduate of Paris; and more recently, his cousin, Patrice MacMabon, also a Doctor of Paris, vas Librarian to the School of Medicine of this city.

Amongst the medical talk of last week there are some topics of interest to your readers. Thus it is said that Pro. fessor Depaul, who occupies the clinical chair of Accouchements at the Faculty, has been invited to Brazil to assist the daughter-in-law of the Emperor in her apr roaching confinement. His honorarium will be a handsome one, $\& 10,000$ and $\$ 2000$ for travelling expenses. Duchenne de Boulogne, the well-known promoter of the medical uses of electricity, and the author of the exhaustive treatise on the same subject is suffering severely from illness. Bouillaud, the veteran clinical professor at the Charité, is contemplating retirement from hospital work, not on account of health, notwith standing his ripe old age of eighty, but to seek rest and quiet after a life of hard work, crowned by every honour and success. The illustrious physician is full of life and vigour, and his intellectual abilities and powers of oratory are as bright as ever.

Paris, Sept. 15th, 1875 .

Bequests, \&c., to Medical Charities.-Mrs: Mary Price, of Woodhatch, Reigate, bequeathed $\$ 500$ to the Sussex County Hospital, $£ 300$ to the Reigate Cottage Hospital, $£ 300$ to the Surrey Dispensary, \&200 to the Opnthalmic Institution in London, $\mathcal{2} 200$ to the Truss Society, 2100 to the Medical Benevolent Society, Epsom, and $£ 100$ to the Asylum for Idiots, Farlswood. Mr. Charles James Kılpin, of Ossington-street, Bayswater, bequeathed $£ 100$ to University College Hospital and $\$ 100$ to the Hampshire Hospital. 